\title{
Toward a New Plant-Wide Experimental and Modeling Approach for Reduction of Greenhouse Gas Emission from Wastewater Treatment Plants
}

\author{
Donatella Caniani ${ }^{1}$; Giovanni Esposito²; Riccardo Gori ${ }^{3}$; Cecilia Caretti ${ }^{4}$; Giacomo Bellandi ${ }^{5}$; \\ Ignazio M. Mancini6; Marianna Caivano7; Raffaella Pascale ${ }^{8}$; Alida Cosenza9; \\ Hafed Abouissa ${ }^{10}$; and Giorgio Mannina ${ }^{11}$
}

\begin{abstract}
Mechanisms causing greenhouse gas (GHG) emission in wastewater treatment plants are of great interest among researchers, encouraging the development of new methods for wastewater management. Wastewater treatment plants (WWTPs) emit three major greenhouse gases during the treatment processes: $\mathrm{CO}_{2}, \mathrm{CH}_{4}$, and $\mathrm{N}_{2} \mathrm{O}$. Additional amounts of $\mathrm{CO}_{2}$ and $\mathrm{CH}_{4}$ are produced during energy consumption, which can be considered an indirect source of GHGs. Recently, several efforts have been undertaken to assess GHGs from WWTPs, with particular attention paid to the $\mathrm{N}_{2} \mathrm{O}$ assessment due to its high warming potential (300 times stronger than $\mathrm{CO}_{2}$ ). This study proposes an integrated model platform for WWTP simulation, including the evaluation of both direct and indirect emissions as plant performance parameters. The results of extensive research demonstrate the importance of mathematical modeling for the development of a decision support system (DSS). The project involves four research units (RUs) united in effort to minimize the environmental impact of wastewater treatment plants in terms of both energy consumption and discharged pollutants (solids, liquids, and gases). DOI: 10.1061/ (ASCE)EE.1943-7870.0001538. ( ) 2019 American Society of Civil Engineers.
\end{abstract}

Author keywords: Decision support system; Energy consumptions; Greenhouse gas (GHG) emissions; Modelling; Wastewater treatment plants (WWTPs).

\section{Introduction}

The assessment of greenhouse gas (GHG) emissions from water resource recovery facilities can be divided into two categories: experimental and modeling (Bani Shahabadi et al. 2009). The experiments are aimed at developing new and more effective measurement techniques for the take-over of GHG measures, which are applied afterwards to understand the mechanisms of formation and emission of such gases (Ahn et al. 2010; Caniani et al. 2019).

The literature shows that an integrated methodology for a better design and management of WWTPs, which include the reduction of GHG emissions, is still lacking (Flores-Alsina et al. 2011; Guo et al. 2016). This knowledge gap is likely due to the lack of adequate data sets containing the seasonal and daily variation of emissions, which take into account the changes in environmental condition, plant operating functions, and site-specific parameters. Indeed, a broad database is essential to build robust and reliable mathematical models to be used as tools for comparing different scenarios (both during plant design and operation) and setting up appropriate mitigation strategies. Moreover, the absence of a standard protocol for gas sampling and measuring makes the setting up of such a database a very ambitious aim. Indeed, data acquired by adopting different sampling and measuring approaches are difficult to compare.

Furthermore, some issues related to GHG emissions, particularly $\mathrm{N}_{2} \mathrm{O}$, from WWTPs still require further research (Mannina et al. 2016c). $\mathrm{N}_{2} \mathrm{O}$ can be produced during the biological nitrogen removal processes (both during nitrification and denitrification) (Kampschreur et al. 2009). Autotrophic ammonia oxidizing bacteria (AOB) can contribute to $\mathrm{N}_{2} \mathrm{O}$ production through two pathways:

\footnotetext{
${ }^{1}$ Associate Professor, Engineering School, Univ. of Basilicata, Viale dell'Ateneo Lucano, 10, 85100 Potenza, Italy (corresponding author). Email: donatella.caniani@unibas.it

${ }^{2}$ Associate Professor, Dept. of Civil, Architectural and Environmental Engineering, Univ. of Napoli "Federico II", via Claudio 21, 80125 Napoli, Italy. Email: gioespos@unina.it

${ }^{3}$ Associate Professor, Dept. of Civil and Environmental Engineering, Univ. of Florence, Via Santa Marta 3, 50139 Florence, Italy. Email: riccardo.gori@dicea.unifi.it

${ }^{4}$ Researcher, Dept. of Civil and Environmental Engineering, Univ. of Florence, Via Santa Marta 3, 50139 Florence, Italy. ORCID: https:// orcid.org/0000-0003-0877-701X. Email: cecilia@dicea.unifi.it

Note. This manuscript was submitted on November 4, 2016; approved on November 19, 2018; published online on May 31, 2019. Discussion period open until October 31, 2019; separate discussions must be submitted for individual papers. This paper is part of the Journal of Environmental Engineering, (C) ASCE, ISSN 0733-9372.
}

${ }^{5}$ Researcher, Dept. of Civil and Environmental Engineering, Politecnico Di Milano, Piazza Leonardo da Vinci, 32, 20133 Milano, Italy. Email: giacomo.bellandi@polimi.it

${ }^{6}$ Full Professor, Engineering School, Univ. of Basilicata, Viale dell'Ateneo Lucano, 10, 85100 Potenza, Italy. Email: ignazio.mancini@ unibas.it

${ }^{7}$ Researcher, Engineering School, Univ. of Basilicata, Viale dell'Ateneo Lucano, 10, 85100 Potenza, Italy. Email: marianna.caivano@unibas.it

${ }^{8}$ Researcher, Engineering School, Univ. of Basilicata, Viale dell'Ateneo Lucano, 10, 85100 Potenza, Italy. Email: raffaella.pascale@unibas.it

${ }^{9}$ Researcher, Dept. of Engineering, Palermo Univ., Viale delle Scienze, Ed. 8, Palermo, PA 90128, Italy. Email: alida.cosenza@unipa.it

${ }^{10}$ Researcher, Dept. of Engineering, Palermo Univ., Viale delle Scienze, Ed. 8, Palermo, PA 90128, Italy. Email: hafed.abouissa@unipa.it

${ }^{11}$ Associate Professor, Dept. of Engineering, Palermo Univ., Viale delle Scienze, Ed. 8, Palermo, PA 90128, Italy. ORCID: https://orcid.org/0000 -0002-5405-7147. Email: giorgio.mannina@unipa.it 
(i) incomplete oxidation of hydroxylamine $\left(\mathrm{NH}_{2} \mathrm{OH}\right)$, which represents and intermediate of the ammonia oxidation; and (ii) reduction of $\mathrm{NO}_{2}^{-}$as a terminal electron acceptor to $\mathrm{N}_{2} \mathrm{O}(\mathrm{AOB}$ denitrification) (Kim et al. 2010; Yu et al. 2010).

Despite numerous attempts to better understand the key issues concerning the $\mathrm{N}_{2} \mathrm{O}$ production/modeling, more studies are needed (Kampschreur et al. 2009; Caniani et al. 2015, 2017). In terms of process knowledge, several studies have been performed to identify the key operating factors or the influent features mostly affecting the $\mathrm{N}_{2} \mathrm{O}$ production (Stenström et al. 2014; Wu et al. 2014). However, these studies have been mainly performed on conventional activated sludge (CAS) systems (Caniani et al. 2019). Therefore, the results are difficult to apply to the behavior WWTP where advanced technology is applied (e.g., membrane bioreactors-MBR, or moving bed biofilm reactors-MBBR). In terms of $\mathrm{N}_{2} \mathrm{O}$ modeling, the use of plant-wide mechanistic dynamic models with a high degree of model complexity still represent a controversial research topic (Mannina et al. 2016b).

The activities and the results presented in this paper belong to the project "Energy consumption of GreenHouse Gas (GHG) emissions in wastewater treatment plants: a decision support system for planning and management," which is founded by Italy's Ministry of Education, University and Research (MIUR). The main aim of the project is the development of an innovative decision support system (DSS) to be adopted as a tool during the design and/or operation of WWTPs to reduce their environmental impacts (in terms of solids, liquid, and gaseous emissions). The reduction of the energy footprint (EFP) and the carbon footprint (CFP) is one of the main objectives of the project.

This paper presents the main methodological features and preliminary results of the project. More precisely, results of the experimental activities on both full-scale and pilot-scale plants are here presented with the main aim to provide information about the operational parameters with the greatest influence on energy consumption and GHG production. The project has been carried out for 3 years by four Italian research units (RUs), which had performed both experimental and modeling activities based on their scientific experience on conventional and advanced treatment of wastewater and sludge. In order to develop an integrated experimental and modeling approach for WWTP management toward the reduction of direct and indirect emissions, which is the ultimate goal of the project, the expertise of each RU has been shared among all other RUs, performing both complementary and independent activities via uniform scientific approaches. The experimental activities have the main objective to evaluate the influence of design and management parameters on energy consumption and GHG production in WWTPs (Caniani et al. 2015). Specifically, the description of the main processes (i.e., physical, chemical, and biological) and the relative GHG emissions occurring along the treatment lines is supported by detailed and simplified mathematical models, subsequently integrated with complex models in order to set up a DSS (Caniani et al. 2015).

This project began with a scientific review by WWTP managers and GHG emission (both direct and indirect) knowledge. The projects takes into account the specific knowledge gained by each RU over the years, allowing the authors to pinpoint all synergies among the different treatment units in both conventional and innovative WWTPs to enable optimization of plant management and design by means of an integrated approach.

\section{Scientific Work of the Research Units}

This project strives to bridge the literature gaps while focusing on global optimization of the WWTP by selecting more cost-efficient solutions to achieve the effluent standard quality and to protect the environment. Four RUs are working on the project: Università di Palermo (RU1), Università della Basilicata (RU2), Università di Cassino e del Lazio Meridionale (RU3), and Università di Firenze (RU4).

RU1 deals with advanced wastewater treatment units, i.e., membrane bioreactors (MBRs). RU1 also has experience in advanced modeling of WWTPs, including calibration and validation of mathematical models by means of local and global sensitivity analysis methods. The gained skills and scientific topics of RU1 have contributed to better investigate nonconventional wastewater treatments. RU1 investigates both physicochemical and biological phenomena occurring along the water line in advanced wastewater treatment systems by means of a MBR pilot plant, operated to remove nutrients from municipal and industrial wastewater. The effects of incoming wastewater characteristics [i.e., chemical oxygen demand (COD) and nutrient loads, influent flow], operational parameters (i.e., sludge and hydraulic retention time), and plant configuration (i.e., denitrification-nitrification-MBR; UCT-MBR; moving bed biofilm reactor-MBR) on GHG production. Emissions are evaluated during the pilot plant operation. Activated sludge models (ASMs) were used as guidelines to build a complex model able to simulate biological and physical phenomena inside the treatment units. The ASMs are coupled with an empirical simplified model to ensure a more reliable and easier application.

RU2 has expertise on the aerobic treatment of activated sludge, including settling, thickening, and aerobic digestion. In previous research projects, experimental tests were performed on secondary settling by operating a pilot-scale treatment unit designed and built by the Engineering School of the Università della Basilicata (Caivano et al. 2017b). Moreover, RU2 has extensive experience in modeling of aerobic processes occurring in a biological tank (Caivano et al. 2015), having developed ASM-type models of activated sludge processes with attention focused on nitrogen removal from wastewater and sludge. Therefore, with a view to a plant-wide approach, RU2 has contributed in defining the experimental tests as well as the modeling approach on the sludge line, particularly on the sludge settling and aerobic digestion. In particular, considering the popularity of aerobic digestion in treating excess sludge in small-to-medium-sized WWTPs $(10,000-50,000$ population equivalents-PE) in Italy (Caivano et al. 2017a), the interest in the contribution of aerobic digestion to the CFP and EFP of WWTPs makes the project even more integrated. According to its previous scientific experience, RU2 has started up a pilot-scale plant with the aim to analyze more effectively the processes of settling and aerobic digestion. The qualitative and quantitative characteristics of the sludge and the plant operational parameters are monitored and collected in a database, increasing knowledge about the influence of management parameters on GHG emissions and to develop and calibrate ASM-based models.

RU3 has gained scientific expertise in operating anaerobic digesters. Considering that anaerobic digestion is a common solution throughout the world for sludge treatment in medium-large WWTPs, the contribution of RU3 in reaching the project goals is of great interest, since the biogas might have an important role in the WWTP carbon mass balance. RU3 has investigated anaerobic digestion processes, providing information on the influence of operational parameters and feeding sludge characteristics on biogas amount, energy savings, and GHG emissions. Experimental tests and modeling activities were carried out, contributing to enlarge the available scientific data set and to develop the simulation platforms.

RU4 has experience in performing field measurement sof oxygen transfer efficiency (OTE) and GHG emissions from wastewater 
treatment units by means of an off-gas apparatus. Therefore, RU4 has proposed a standard protocol as a fundamental result of this project, in order to support other RUs in conducting measurement campaigns on both pilot-scale and full-scale treatment units in conventional and innovative plants. This standard protocol has allowed to evaluate OTE in aerated units (i.e., activated sludge tanks), as well as to assess GHG emissions, carrying out the experimental tests in a comparable way. RU4 has performed experimental tests on both conventional and innovative plants, identifying the operative parameters that most influence the production and emission of GHGs.

\section{Materials and Methods}

\section{Experimental Activities}

\section{Pilot Plant and the Sampling Campaign of RU1}

A University Cape Town (UCT) membrane bioreactor (MBR) pilot plant was monitored according to two different configurations (I and II) (Fig. 1). Configuration I represents a UCT-MBR scheme, while Configuration II represents an integrated fixed film activated sludge (IFAS) MBR system. For both configurations, the pilot plant consisted of anaerobic (volume $62 \mathrm{~L}$ ), anoxic (volume $102 \mathrm{~L}$ ), and aerobic (volume $211 \mathrm{~L}$ ) compartments according to the UCT scheme. The solid-liquid separation phase was achieved by means of an ultrafiltration hollow fiber membrane module (PURON Triple bundle Demo Module; nominal pore size $0.03 \mu \mathrm{m}$, membrane area $1.4 \mathrm{~m}^{2}$ ), located inside a dedicated aerated compartment (MBR tank, $36 \mathrm{~L})$. An oxygen depletion reactor (ODR) allowed oxygen removal in the mixed liquor recycled from the MBR tank to the anoxic tank $\left(\mathrm{Q}_{\mathrm{RAS}}\right)$. The membrane was periodically backwashed (every 9 min for a period of $1 \mathrm{~min}$ ) by pumping a volume of permeate back through the membrane fibers from the clean-in-place (CIP) tank. During the operation of the pilot plant according to Configuration II, the anoxic and aerobic compartments were filled with suspended carriers (Amitech s.r.1.) with a $15 \%$ and $40 \%$ filling fraction, respectively. For both configurations, the influent flow rate was set equal to $20 \mathrm{~L} \mathrm{~h}^{-1}\left(\mathrm{Q}_{\mathrm{IN}}\right)$. The anaerobic, anoxic, aerobic, and MBR reactors were equipped with specific covers that guaranteed gas accumulation in the headspace to perform the gas sampling. The pilot plant was monitored for 100 days according to Configuration I and for 251 days according to Configuration II. During the operation of Configuration I, the influence of the $\mathrm{C} / \mathrm{N}$ ratio $(\mathrm{C} / \mathrm{N}=10$ and $\mathrm{C} / \mathrm{N}=5)$ on the $\mathrm{N}_{2} \mathrm{O}$ emission and on the plant performance was investigated (Mannina et al. 2016a). During the operation of Configuration II, the influence of several operating conditions and influent features on the $\mathrm{N}_{2} \mathrm{O}$ emission and on the plant performance was investigated. More specifically, the following operating conditions were investigated: $\mathrm{C} / \mathrm{N}$ ratio $(\mathrm{C} / \mathrm{N}=10$, $\mathrm{C} / \mathrm{N}=5$ and $\mathrm{C} / \mathrm{N}=2.5$ ); sludge retention time (SRT) (SRT = indefinite; $\mathrm{SRT}=30$ days; SRT $=15$ days); and the air flow rate for membrane fouling mitigation. During the pilot plant operation (for both configurations), samples were withdrawn in order to analyze the performance of the system in terms of COD, N, and $\mathrm{P}$ removal. Furthermore, $\mathrm{N}_{2} \mathrm{O}$ dissolved in the liquid phase and in the gas samples was analyzed. $\mathrm{N}_{2} \mathrm{O}$ concentration was measured using a gas chromatograph (Thermo Scientific TRACE GC) equipped with an electron capture detector.

Pilot Plant and the Full-Scale Sampling Campaign of RU2

Fig. 2 illustrates the pilot plant for aerobic digestion, which was a cylindrical aerated tank connected to an off-gas capture equipment. An aeration system, with an air flow rate of $0.05 \mathrm{~m}^{3} \mathrm{~h}^{-1}$, was applied to a $10-\mathrm{L}$ polyethylene tank. A mixer was introduced to avoid the settling of sludge particles and, at the same time, to ensure a well-mixed system without anoxic dead zones during aeration periods.

At the beginning of the experiment, the digester was fed with $6 \mathrm{~L}$ of the activated sludge from the underflow of a full-scale secondary settler. Then, $0.06 \mathrm{~L}$ of the same sludge were added each day in order to refill the same discharged quantity. A 30-day monitoring campaign was carried out. At the end of the first 10 days, the equilibrium conditions of the aerobic digester were reached; whereas, the other were used days to complete the process (assuming 20 days as SRT).

The pilot digester was monitored by analyzing the influent and discharged sludge regarding the concentration of COD, total suspended solids (TSS), volatile suspended solids (VSS), ammonium $\left(\mathrm{N}-\mathrm{NH}_{4}^{+}\right)$, nitrites $\left(\mathrm{N}-\mathrm{NO}_{2}^{-}\right)$, and nitrates $\left(\mathrm{N}-\mathrm{NO}_{3}^{-}\right)$. Table 1 lists the results of these analyses, reporting an average value of influent and discharged sludge characteristics.

A $50.9 \%$ decrease in VSS concentration and a $36.7 \%$ decreae in TSS concentration were observed after 20 days of digestion; these values are very close to the range suggested in the literature for well performing systems $(38 \%-50 \%$ in VSS and $30 \%-50 \%$ in TSS; Metcalf \& Eddy 2003).

Furthermore, knowing that the quantity of produced GHG is mainly influenced by the influent wastewater, analyses of the

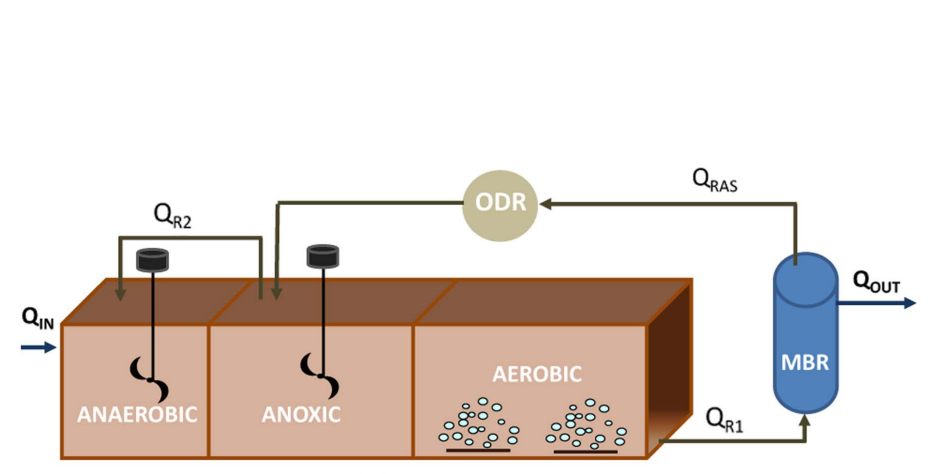

(a)

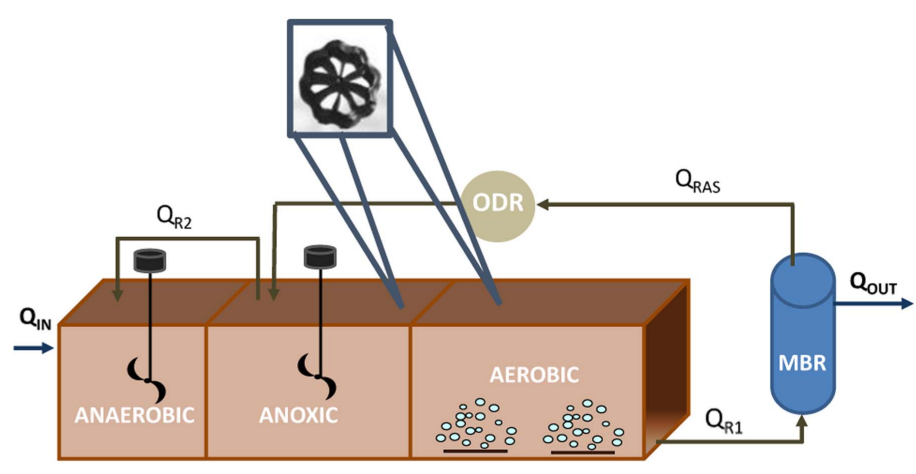

(b)

Fig. 1. Layout of the UCT-MBR pilot plant according to (a) Configuration I; and (b) Configuration II. $\mathrm{Q}_{\mathrm{IN}}=$ influent wastewater; $\mathrm{Q}_{\mathrm{R} 2}=$ mixed liquor recycled from the anoxic to the anaerobic tank; $\mathrm{Q}_{\mathrm{R} 1}=$ mixed liquor recycled from the aerobic to the $\mathrm{MBR}$ tank; $\mathrm{Q}_{\mathrm{RAS}}=$ recycled sludge from the $\mathrm{MBR}$ to the anoxic tank; Qout $=$ effluent permeate flow rate; and ODR = oxygen depletion reactor. 


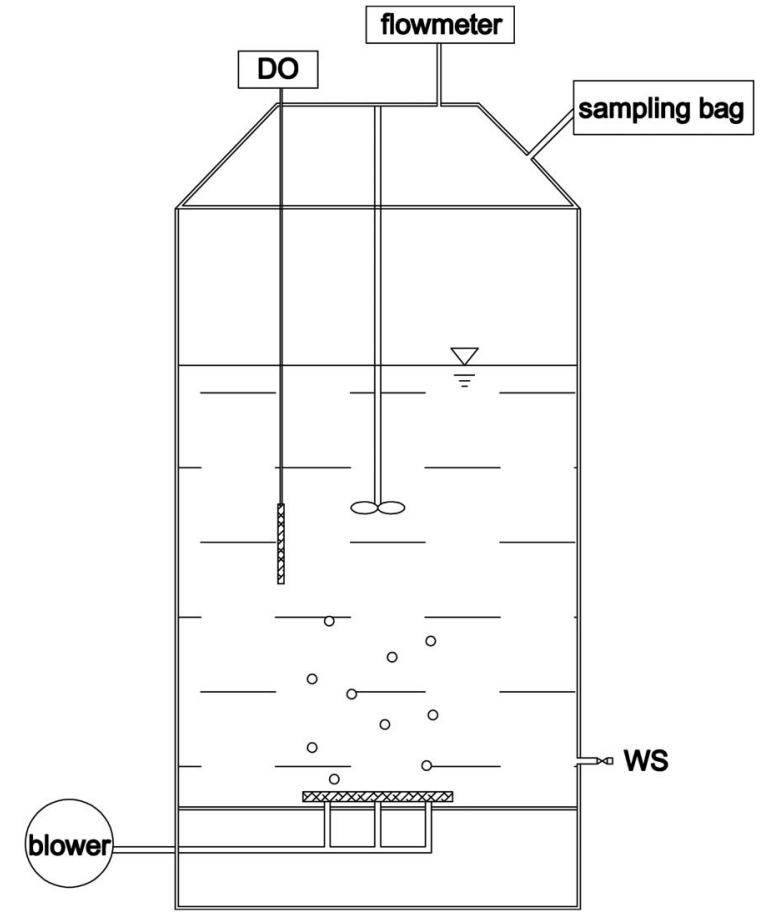

Fig. 2. Simplified drawing of the pilot apparatus $(\mathrm{DO}=$ dissolved oxygen).

Table 1. Sludge characteristics (all values are expressed in $\mathrm{mg} / \mathrm{L}$ )

\begin{tabular}{lcccccc}
\hline Sludge & COD & TSS & VSS & $\mathrm{NH}_{4}^{+}$ & $\mathrm{N}_{-} \mathrm{NO}_{2}^{-}$ & $\mathrm{N}_{-} \mathrm{NO}_{3}^{-}$ \\
\hline $\begin{array}{l}\text { Influent sludge at } \\
\text { first day test }\end{array}$ & $6,141.2$ & 10,720 & 8,200 & 2.3 & 1.1 & 132.9 \\
$\begin{array}{l}\text { Discharged sludge } \\
\text { after 20 days }\end{array}$ & $5,130.5$ & 6,780 & 4,045 & 3.0 & 1.8 & 277.5 \\
\hline
\end{tabular}

wastewater influent in the reference full-scale plant were performed. Aerobic digestion (AeD) of a full-scale WWTP was also monitore. The studied WWTP is located in southern Italy and serves $15,000 \mathrm{PE}$ (with a flow of about $3,700 \mathrm{~m}^{3}$ per day) and treats wastewater by means of a modified Ludzak-Ettinger (MLE) layout. The off-gas measurements were performed during a 3-day monitoring campaign. Influent and effluent features in terms of COD, TSS, N-NH,$+ \mathrm{N}_{4} \mathrm{NO}_{2}^{-}$, and $\mathrm{N}_{-} \mathrm{NO}_{3}^{-}$were monitored during the testing days.

Both the aerobic bioreactor and AeD were monitored using the described off-gas technique to evaluate AeD and $\mathrm{CO}_{2}$ and $\mathrm{N}_{2} \mathrm{O}$ emissions. Features of the influent wastewater and effluent mixed liquor of the oxidation tank were needed in order to investigate treatment efficacy and GHG emissions. Therefore, the concentration of $\mathrm{COD}, \mathrm{N}-\mathrm{NH}_{4}^{+}, \mathrm{N}_{-} \mathrm{NO}_{2}^{-}$, and $\mathrm{N}-\mathrm{NO}_{3}^{-}$were measured on the first day as reported in Table 2.

To determine the AeD, only the GHG emissions were measured due to the presence of surface aerators. Fig. 3 shows the location of GHG the sampling points.

The exhaust gas was collected in the hood headspace by keeping all available connections closed, except for one connected to a Teflon tube. A portion of the Teflon tube, with a diameter of $3 \mathrm{~mm}$, was siphon shaped and filled with water, in order to measure the relative pressure increase, and thus the flux of the gases leaving the liquid surface.
Table 2. Characteristics of the influent and effluent from the oxidation tank

\begin{tabular}{llccc}
\hline Tests & & $2: 00$ p.m. & $3: 00$ p.m. & $4: 00$ p.m. \\
\hline COD $(\mathrm{mg} / \mathrm{L})$ & Influent & 675 & 1,448 & 2,051 \\
& Effluent & 9,420 & 10,220 & 11,860 \\
$\mathrm{COD}(\mathrm{mg} / \mathrm{L})$ & Influent & 82 & 180 & 202 \\
& Effluent & 231 & 91 & 281 \\
$\mathrm{TSS}(\mathrm{mg} / \mathrm{L})$ & Influent & 366 & 1,230 & 1,640 \\
& Effluent & 10,140 & 9,680 & 8,600 \\
$\mathrm{NH}^{4+}(\mathrm{mg} / \mathrm{L})$ & Influent & 55.62 & 44.95 & 50.74 \\
& Effluent & 34.46 & 35.9 & 43.51 \\
$\mathrm{~N}^{-N O}{ }^{3-}(\mathrm{mg} / \mathrm{L})$ & Influent & 0.86 & 0.27 & 0.01 \\
& Effluent & 0.2 & 0.36 & 0.003 \\
$\mathrm{~N}^{2} \mathrm{NO}^{2-}(\mathrm{mg} / \mathrm{L})$ & Influent & 0 & 0 & 0.1 \\
& Effluent & 0 & 0 & 0 \\
\hline
\end{tabular}

\section{Batch Tests and Measures Conducted by RU3}

Different sludge types, collected from several CAS and MBR real scale treatment plants, were concentrated by settling for $2 \mathrm{~h}$. Thus, the thickened sludges were described by gravimetry in terms of TS-VS as stated by EPA standard methods [EPA 1684 (USEPA Office of Water 2001)]. A portion of each thickened sludge underwent an extracellular polymeric substances (EPS) extraction as described by Frølund et al. (1995). Dowex marathon C (SigmaAldrich) was selected as cation exchange resin (CER). The EPS composition was then defined in terms of carbohydrates $(\mathrm{CH})$ (Dubois et al. 1956), uronic acids (UA) (Blumenkrantz and AsboeHansen 1973; Kintner and Van Buren 1982), proteins (PR) (Lowry et al. 1951), and humic substances (HA) (Frølund et al. 1995).

Biomethanation batch tests (BMTs) (Pontoni et al. 2015) were carried out on $400 \mathrm{~mL}$ of each sludge, in triplicate and under controlled and reproducible conditions in a 1,000-mL glass bottle (Schott Duran, Germany). A 5-mm silicone disc was held tightly to each bottle head by a plastic screw cap punched in the middle (Schott Duran, Germany). The bottles were submerged up to half of their depth in a water bath at a constant temperature of $308 \mathrm{~K}$. Methane yield was measured periodically by the water displacement method: the biogas was left bubbling in an upturned $1,000-\mathrm{mL}$ bottle containing a $12 \% \mathrm{NaOH}$ solution, in order to capture the $\mathrm{CO}_{2}$ present in the biogas. The methane measurement was stopped once the daily biogas production was lower than $1 \%$ of the total biomethanation potential (BMP). The results are expressed in $\mathrm{NmL} / \mathrm{gVS}$ as specific methane potential (SMP). Dewaterability was estimated by calculating the specific resistance to filtration (SRF) (Pontoni et al. 2015; Chen et al. 2015). The capillary suction time (CST) was calculated by means of a Triton (UK) standard CST equipment with a 18-mm-diameter funnel on standard CST paper following APHA standard method 2710G (APHA, AWWA, and WEF 1998).

\section{Off-Gas Analyzer Developed by RU4}

An off-gas analyzer setup (Fig. 4) was designed for measuring aeration efficiency of submerged aeration systems and full-scale direct GHG emissions in the form of $\mathrm{N}_{2} \mathrm{O}, \mathrm{CO}_{2}$, and $\mathrm{CH}_{4}$ biologically generated and/or stripped from activated sludge (AS) oxidation tanks (Gori et al. 2016).

The gas stream leaving the liquid tank (off-gas) is captured by a floating hood, and a hot wire anemometer (8455 Series, TSI) measures the flow rate. A small fraction $(1 \mathrm{~L} / \mathrm{min})$ of the off-gas captured is spilled by a vacuum pump and directed to the analyzer. A desiccator unit performs the first conditioning of the gas sample in order to remove water vapor. The spilled air flow is then circulated inside a zirconium oxide fuel cell (AMI Model 65, Advanced 


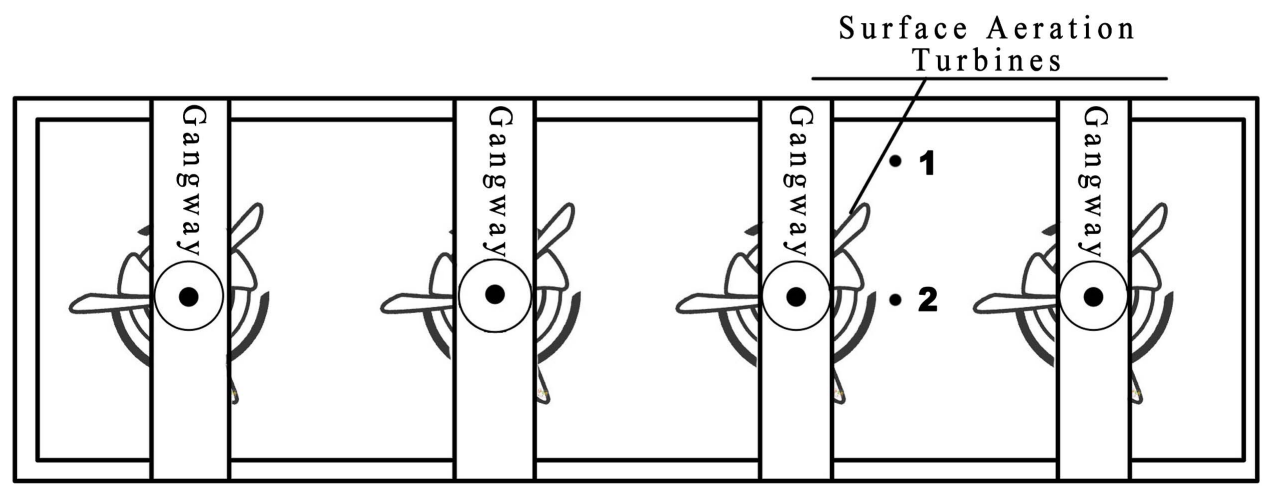

Fig. 3. Sampling points of the aerobic digestion tank.

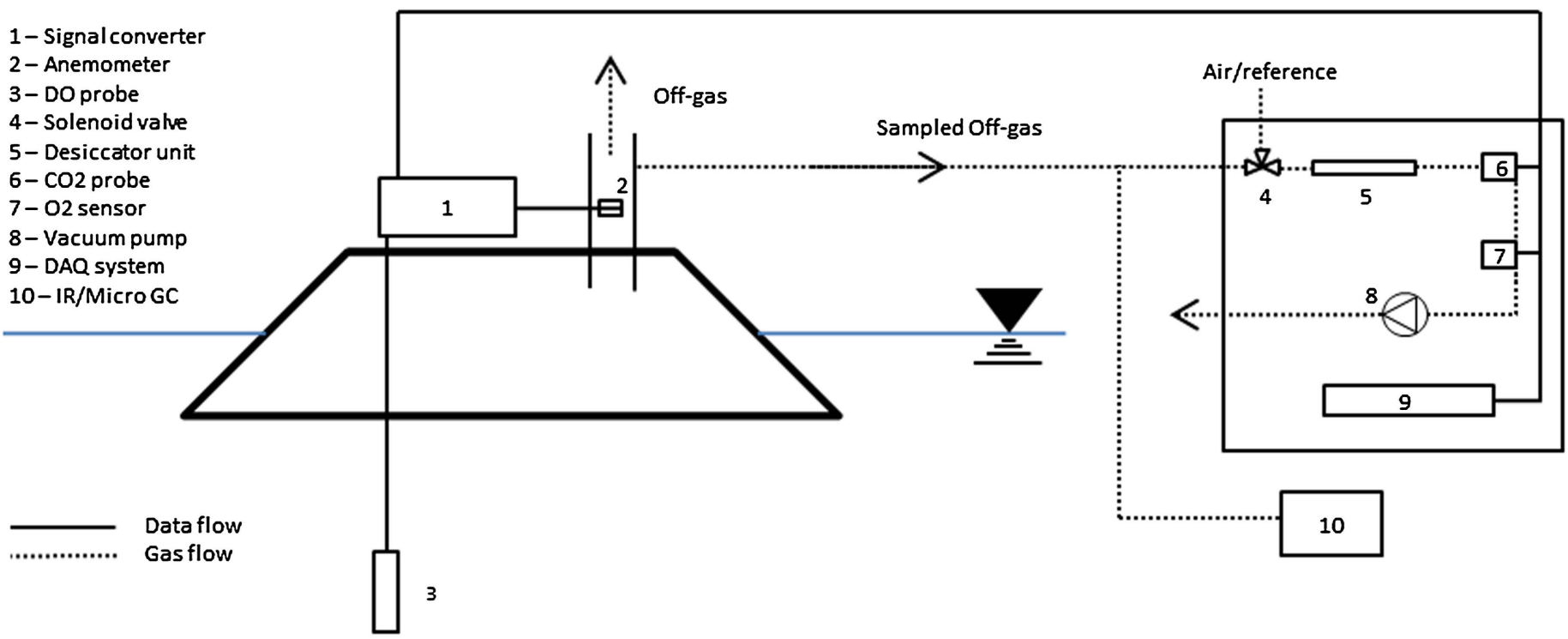

Fig. 4. Schematic of the off-gas analyzer setup.

Micro Instruments, Costa Mesa, California) to measure oxygen partial pressure. Ambient air was sampled using a three-way valve at the start and end of each experiment to determinte the reference for evaluating the OTE. The dissolved oxygen (DO) in the mixed liquor is simultaneously measured.

The coupling of off-gas analyzers and portable microgas chromatograph (CG) units allowed high-resolution online measurements of GHGs with concurrent OTE measurements. The GHG partial pressure can be converted to emission rates once the off-gas flow rate is known.

When the humidity is stripped out of the gas stream, knowing the $\mathrm{CO}_{2}$ content is necessary in order to calculate the actual mass fraction of oxygen. For this purpose, the $\mathrm{CO}_{2}$ content of both the ambient air and the off-gas stream was measured with a photoacoustic infrared gas analyzer (X-Stream, Emerson). Knowing the $\mathrm{CO}_{2}$ content of the gas stream, the partial pressure of oxygen and its ratio with inert were calculated using Eqs. (1) and (2):

$$
\begin{gathered}
M R_{o / i}=\frac{Y_{r}}{1-Y_{r}-Y_{\mathrm{CO}_{2} r}} \\
M R_{o g / i}=\frac{Y_{o g}}{1-Y_{o g}-Y_{\mathrm{CO}_{2} o g}}
\end{gathered}
$$

Finally, the OTE can be calculated with Eq. (3) accounting for the dynamic $\mathrm{CO}_{2}$ content in the off-gas. Finally, a standardized value OTE can be calculated for either new ( $\alpha S O T E)$ or used $(\alpha F S O T E)$ diffusers with Eq. (4):

$$
\begin{gathered}
\text { OTE }=\frac{\left(O_{2, \text { in }}-O_{2, \text { out }}\right)}{\left(O_{2, \text { in }}\right)} \\
\alpha S O T E=O T E \cdot \frac{C_{S_{20}}^{*}}{\left(\beta \cdot C_{S_{T}}^{*}-C_{i}\right)} \cdot \theta^{(20-T)}
\end{gathered}
$$




$$
\begin{gathered}
\alpha=\frac{\alpha S O T E}{S O T E} \\
F=\frac{\alpha F S O T E}{\alpha S O T E}
\end{gathered}
$$

The contribution of the aeration system to internal indirect emissions of GHG can be calculated through its power demand, energy consumption, and the carbon emission intensity for power generation. If the power demand and energy consumption of aeration systems is not monitored, it can be estimated using the characteristic curves of electromechanical devices involved in the aeration system (e.g., blowers) but only if the air-flow rate is known. The off-gas method can be used to measure the air flow supplied to the aeration system and its spatial variability, by measuring the air flow exiting the aerobic tanks. The measured air flow can be normalized for the surface covered by the hood and extended to the whole reactor surface.

\section{Modeling Activities}

\section{Mathematical Modeling Activities of RU1}

An ASM, subdivided into a biological and physical model, was structured. The biological submodel includes 16 biological processes (aerobic and anoxic); 19 state variables, including dissolved $\mathrm{N}_{2} \mathrm{O}$ and $\mathrm{CO}_{2}$; and 68 model parameters. The processes of nitrogen removal are characterized by a two-step nitrification and four-step denitrification. For this purpose, an ammonia-oxidizing biomass $\left(\mathrm{X}_{\mathrm{AOB}}\right)$ and a nitrite-oxidizing biomass $\left(\mathrm{X}_{\mathrm{NOB}}\right)$ have been modeled. Concerning the denitrification, four correction factors for the anoxic growth rate of heterotrophic biomass have been used. Specifically, factors related to the reduction from $\mathrm{S}_{\mathrm{NO} 3}$ to $\mathrm{S}_{\mathrm{NO} 2}\left(\mu_{\mathrm{g} 2}\right), \mathrm{S}_{\mathrm{NO} 2}$ to $\mathrm{S}_{\mathrm{NO}}\left(\mu_{\mathrm{g} 3}\right), \mathrm{S}_{\mathrm{NO}}$ to $\mathrm{S}_{\mathrm{N} 2 \mathrm{O}}\left(\mu_{\mathrm{g} 4}\right)$, and $\mathrm{S}_{\mathrm{N} 2 \mathrm{O}}$ to $\mathrm{S}_{\mathrm{N} 2}\left(\mu_{\mathrm{g} 5}\right)$ have been considered. The biological model takes into account the influence of the salinity both for the autotrophic and heterotrophic biomass. The developed model has been applied to the pilot plant, which was filled with saline wastewater in agreement with the fill-draw-batch operation. The model was calibrated by using a specific protocol based on a large data set. The data set was acquired during a previous experimental campaign (Mannina et al. 2016c).

\section{Mathematical Modeling Activities of RU3}

The differential mass balance equations for the substrate and the product are the basis of the developed mathematical model. Organic matter, measured as COD, is the only substrate taken into consideration. The rate of the anaerobic digestion process is assumed to be limited by the rate of hydrolysis of the most complex macromolecules. Particularly, a variant of the surface based kinetic (SBK) method was applied.

The following equations constitute the developed model:

$$
\begin{aligned}
& \frac{d S}{d t}=-K_{s b k} a \frac{S}{K_{S}+S} \\
& \frac{d P}{d t}=\sigma K_{s b k} a \frac{S}{K_{S}+S} \\
& \frac{d X}{d t}=\sigma K_{s b k} a \frac{S}{K_{S}+S}
\end{aligned}
$$

Assuming that all the organic particles have the same spherical form and dimension and are progressively degraded from the outside to the inside (Esposito et al. 2011, 2012), $a^{*}$ can be determined with the following equation:

$$
a^{*}=\frac{3}{\mu R}
$$

where $\mu$ is the density and $R$ is the radius of the organic particles, which is assumed to be a function of the time, in accordance with the following equation:

$$
R=R_{0}-K_{s b k} \frac{t}{\mu}
$$

\section{Results and Discussion}

\section{Main Results of RU1}

\section{$\mathrm{N}_{2} \mathrm{O}$ Emissions}

A synthesis of the RU1 experimental outcomes is presented in Fig. 5. These results are related to the $\mathrm{N}_{2} \mathrm{O}$ concentration in the off-gas withdrawn from the anaerobic, anoxic, aerobic, and MBR tanks. By analyzing the data reported in Fig. 5(a), it is possible to observe that low $\mathrm{C} / \mathrm{N}$ values promote an increase in the $\mathrm{N}_{2} \mathrm{O}-\mathrm{N}$ concentration. Indeed, the average value of $\mathrm{N}_{2} \mathrm{O}-\mathrm{N}$ concentration at $\mathrm{C} / \mathrm{N}=5$ is one order of magnitude greater than that of $\mathrm{C} / \mathrm{N}=10$. This result is likely due to the limited heterotrophic activity at low carbon values. Regarding Configuration II [Fig. 5(b)], the average value of $\mathrm{N}_{2} \mathrm{O}-\mathrm{N}$ concentration increases with decrease of the SRT. This result, mainly evident at SRT $=15$ days, is likely due to the decrease of the autotrophic biomass that causes the growth of $\mathrm{N}_{2} \mathrm{O}$ production in the course of the nitrification.

Mathematical Modeling-Calibrated Model and Uncertainty Fig. 6 shows results related to the model application in terms of $\mathrm{N}_{2} \mathrm{O}$ both in liquid and off-gas phases. Data reported in Fig. 6 show that the uncertainty band width (as average difference between $95 \%$ and $5 \%$ percentile) changes with the model outputs in the different plant sections (e.g., greater for $\mathrm{S}_{\mathrm{GHG}, \mathrm{N} 2 \mathrm{O}, 1}$ and $\mathrm{S}_{\mathrm{N} 2 \mathrm{O}, 2}$ ). This is primarily induced because some model results involve different grades of complexity dealing with involved processes in all the sections of the plant. Moreover, the change of several coefficients could make more ambiguous the $\mathrm{N}_{2} \mathrm{O}$ production because of the crossover effects of various processes. By analyzing the data in Fig. 6, one can notice that a more thorough model output can be obtained when a larger number of measured data were available $\left(\mathrm{S}_{\mathrm{GHG}, \mathrm{N} 2 \mathrm{O}, 1}\right.$ and $\mathrm{S}_{\mathrm{GHG}, \mathrm{N} 2 \mathrm{O}, 2}$ ). Indeed, for $\mathrm{S}_{\mathrm{GHG}, \mathrm{N} 2 \mathrm{O}, 1}$ and $\mathrm{S}_{\mathrm{GHG}, \mathrm{N} 2 \mathrm{O}, 2}$ only $7 \%$ and $12 \%$ of the measured data are fall outside the extent of the band.

Fig. 6 provides the cumulative distribution functions (CDFs) of calibrated, measured, 5th and 95th percentiles for (a) $\mathrm{S}_{\mathrm{GHG}, \mathrm{N} 2 \mathrm{O}, 1}$, (b) $\mathrm{S}_{\mathrm{N} 2 \mathrm{O}, 1}$, (c) $\mathrm{S}_{\mathrm{GHG}, \mathrm{N} 2 \mathrm{O}, 2}$, and (d) $\mathrm{S}_{\mathrm{N} 2 \mathrm{O}, 2}$.

These results are of paramount interest and suggest that an extensive database is required to set up accurate models and to reduce the model uncertainty associated with the model predictions. Indeed, $60 \%$ and $46 \%$ of the measured data lay outside the band width for $\mathrm{S}_{\mathrm{N} 2 \mathrm{O}, 1}$ and $\mathrm{S}_{\mathrm{N} 2 \mathrm{O}, 2}$, respectively. More exactly, data lower than 0.01 and $0.025 \mathrm{mgNL}^{-1}$ fall outside the band for $\mathrm{S}_{\mathrm{N} 2 \mathrm{O}, 1}$ and $\mathrm{S}_{\mathrm{N} 2 \mathrm{O}, 2}$.

\section{Main Results of RU2}

The $\mathrm{N}_{2} \mathrm{O}$ concentrations in the off-gas of the pilot reactor and $\mathrm{NH}_{3}$ concentrations in sludge are shown in Figs. 7(a and b) (Caniani et al. 2015). At the beginning of the testing campaign, $\mathrm{N}_{2} \mathrm{O}$ emissions had values in the range $0.136-0.344 \mathrm{ppm}$, close to those obtained in the literature from activated sludge units (Butler et al. 2009). Moreover, the increase of $\mathrm{N}_{2} \mathrm{O}$ concentration in the off-gas flow along with that of SRT can be observed. Fig. 7(a) compares 


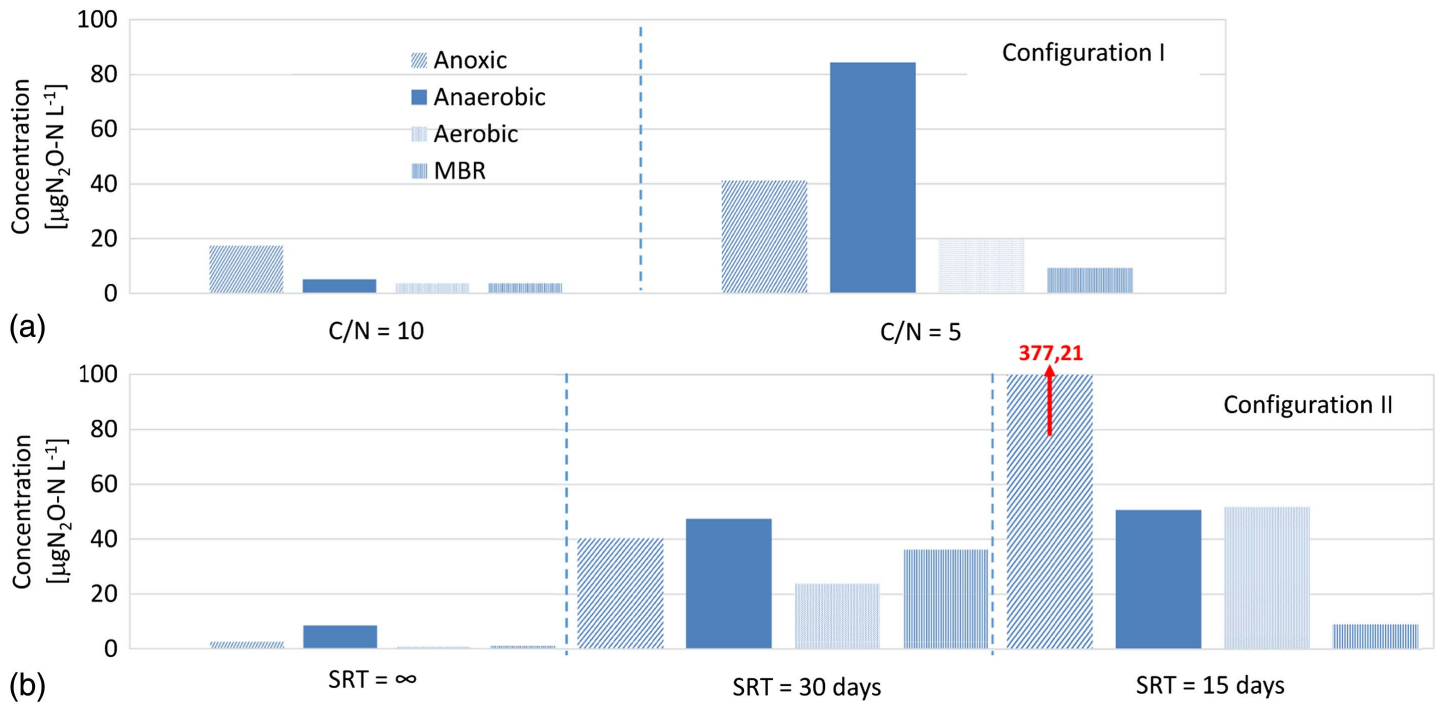

Fig. 5. Average $\mathrm{N}_{2} \mathrm{O}-\mathrm{N}$ concentration in the off-gas withdrawn from the anaerobic, anoxic, aerobic, and MBR tanks for (a) Configuration I; and (b) Configuration II for the investigated operating conditions.

the trend of $\mathrm{N}_{2} \mathrm{O}$ with that of $\mathrm{COD} / \mathrm{N}$ ratio, showing that nitrification is very important in $\mathrm{N}_{2} \mathrm{O}$ production and contributes to $\mathrm{N}_{2} \mathrm{O}$ emission at low COD/N ratios (Desloover et al. 2012). Fig. 7(b) highlights the influence of nitrification on $\mathrm{N}_{2} \mathrm{O}$ fate during aerobic digestion, showing the increase of $\mathrm{N}_{2} \mathrm{O}$ in the off-gas with the decrease of $\mathrm{NH}_{3}$ concentration in the sludge.

Concerning the measurements carried out on a full-scale WWTP, as expected, the results show that the emissions from the aerobic digestion are smaller than those from activated sludge (AS). This is mainly because of the low off-gas flow rates due to the installation of surface turbines as an alternative to submerged diffusers that provide a smaller stripping effect. Total emissions of $\mathrm{CO}_{2 \text {,eq }}$ are shown in Table 3 and compared to other literature results.

Values reported in Table 3 show that the net energy power generation contributes to about $69 \%$ of the total emissions, confirming that aeration systems are the main contributors. As shown in Table 3, the characteristic quantity of $\mathrm{CO}_{2}$ released from AS and $\mathrm{AeD}$ and caused by the biodegradation of organic matter has been calculated based on aeration using fine bubble diffusers in both
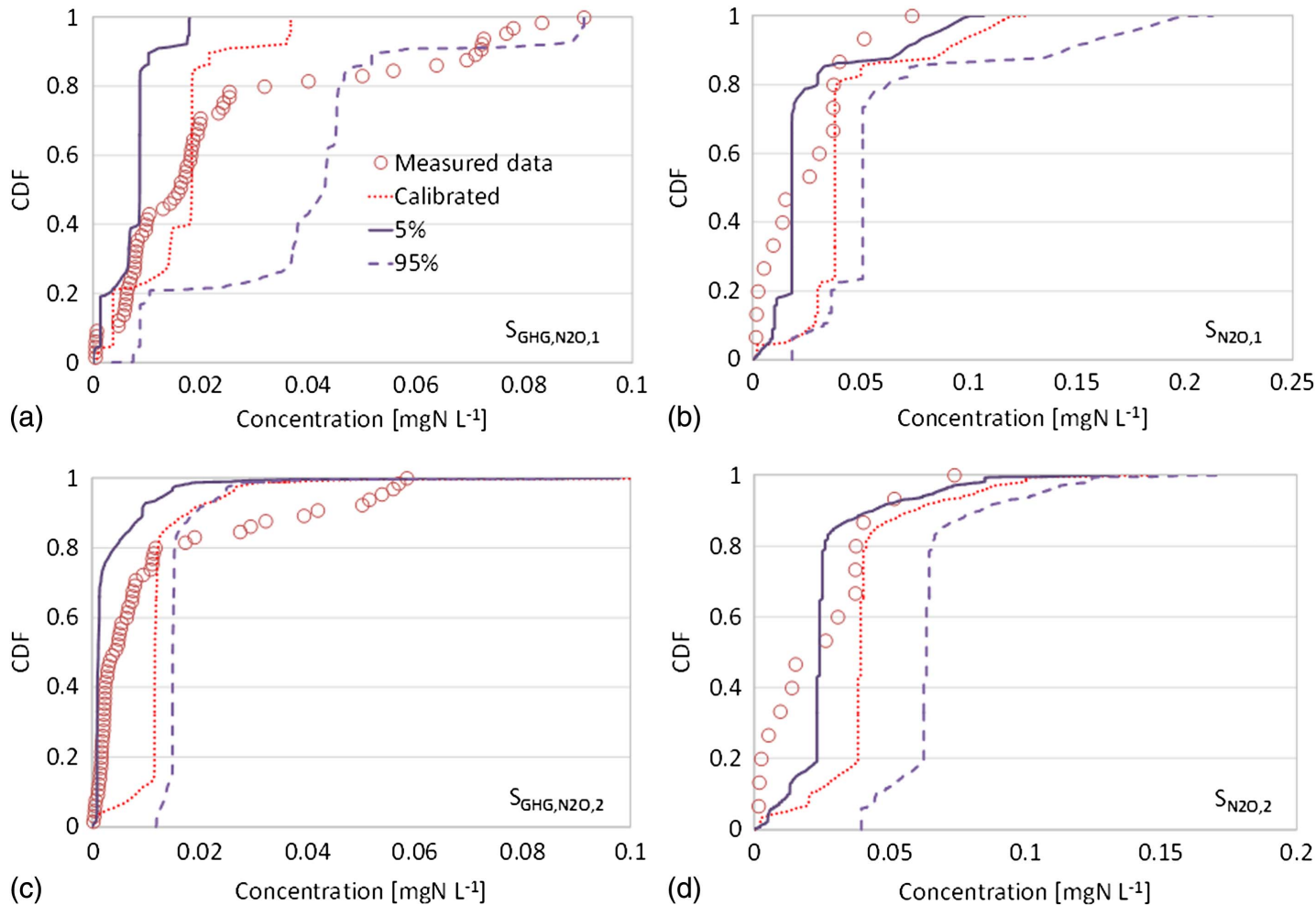

Fig. 6. CDF related to the measured data, calibrated model, $5 \%$ and $95 \%$ percentiles for (a) $\mathrm{S}_{\mathrm{GHG}, \mathrm{N} 2 \mathrm{O}, 1}$; (b) $\mathrm{S}_{\mathrm{N} 2 \mathrm{O}, 1}$; (c) $\mathrm{S}_{\mathrm{GHG}, \mathrm{N} 2 \mathrm{O}, 2}$; and (d) $\mathrm{S}_{\mathrm{N} 2 \mathrm{O}, 2}$. 

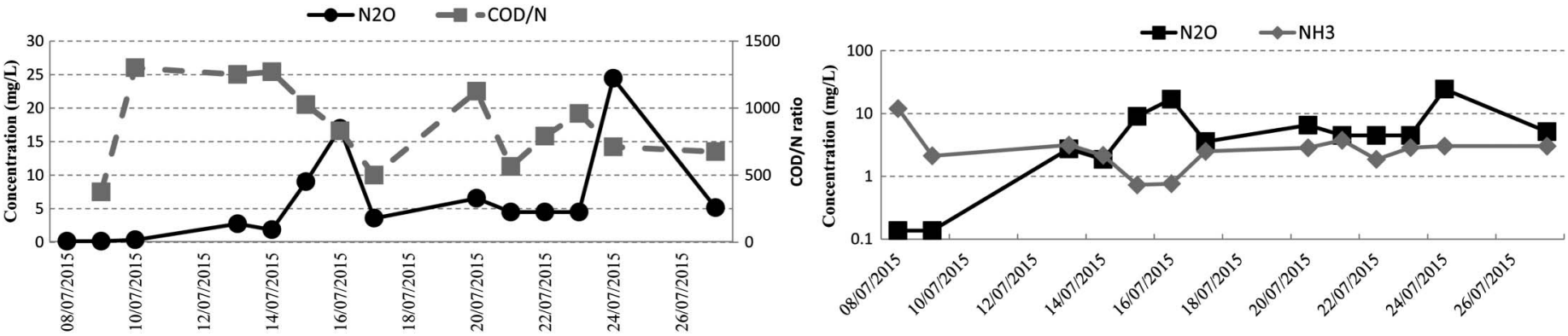

Fig. 7. (a) $\mathrm{N}_{2} \mathrm{O}$ concentration in the off-gas of the aerobic digester and COD/N ration in the reactor; and (b) $\mathrm{N}_{2} \mathrm{O}$ concentration in the off-gas of the aerobic digester and $\mathrm{NH}_{3}$ concentration in the reactor. (Data from Caniani et al. 2015.)

Table 3. Total plant CFP (all values in $\mathrm{kgCO}_{2, \mathrm{eq}} / \mathrm{kg}_{\mathrm{bCOD}}$ ) and comparison with literature data

\begin{tabular}{lcccc}
\hline $\begin{array}{l}\text { Plant units and } \\
\text { literature data }\end{array}$ & $\begin{array}{c}\text { From electricity } \\
\text { production }\end{array}$ & $\begin{array}{c}\text { Direct } \mathrm{CO}_{2} \\
\text { emission }\end{array}$ & $\begin{array}{c}\text { Direct } \mathrm{N}_{2} \mathrm{O} \\
\text { emission }\end{array}$ & $\begin{array}{c}\text { Plant } \\
\text { CFP }\end{array}$ \\
\hline AS & 0.26 & 0.14 & 0.007 & 0.47 \\
AeD & 0.063 & $\begin{array}{c}3 \times 10^{-10} \\
4 \times 10^{-9}\end{array}$ & \\
Gori et al. (2013) & 0.6 & $\begin{array}{c}0.6 \text { from AS } \\
0.4 \text { from AeD }\end{array}$ & 0.1 & 1.7 \\
& \multicolumn{5}{c}{. } \\
\hline
\end{tabular}

Sources: Data from Caivano et al. (2017a); Gori et al. (2013).

the AS and AeD tank. At $20^{\circ} \mathrm{C}$ temperature and an SRT of 10 days, the direct $\mathrm{CO}_{2}$ emissions from $\mathrm{AS}$ and $\mathrm{AeD}$ were about 0.60 and $0.40 \mathrm{~kg}_{\mathrm{CO} 2} / \mathrm{kg}_{\mathrm{bCOD}}$, respectively. The $\mathrm{N}_{2} \mathrm{O}$ contributed to a total amount of $\mathrm{CO}_{2}$ equivalent equal to $0.1 \mathrm{~kg}_{\mathrm{CO} 2} / \mathrm{kg}_{\mathrm{bCOD}}$, while the corresponding total $\mathrm{CO}_{2}$ from electricity generation was $0.6 \mathrm{~kg}_{\mathrm{CO} 2} / \mathrm{kg}_{\mathrm{bCOD}}$. The differences with the literature data are due to the COD fractionation and depend on the presence of the primary clarifier, too. The emissions reported by Gori et al. (2013) are higher than those calculated in this study.

The $\mathrm{N}_{2} \mathrm{O}$ emission fraction was calculated by normalizing the flux to the daily influent total Kjeldahl nitrogen (TKN), following Chandran (2011). Considering an average value of the influent $\mathrm{NH}_{4}^{+}$of $52.4 \mathrm{mg} / \mathrm{L}$, the value obtained for the emission fraction is $0.00032 \mathrm{~kg}_{\mathrm{N} 2 \mathrm{O}-\mathrm{N}} / \mathrm{kg}_{\mathrm{NH} 4-\mathrm{N}}$, corresponding to $0.032 \%$ of influent TKN. The obtained value is inside the range indicated by Chandran (2011) for AS, but closer to its lower bound. This situation is not due to the low-emission configuration of the plant, but most probably because many anoxic zones are generated in the aerobic reactor due to the scarce efficiency of the aeration system. One possible explanation is that $\mathrm{N}_{2} \mathrm{O}$ production takes place in the liquid phase and it is not stripped in the gas phase due to coarse bubbles and low aeration efficiency. Indeed, the daily rate of $\mathrm{N}_{2} \mathrm{O}$ emitted from the aeration tank is $70 \mathrm{~g}_{\mathrm{N} 2 \mathrm{O}} /$ day, which is a typical result obtained for anoxic reactors, as shown by Ahn et al. (2010).

\section{Main Results of RU3}

The main results of the experimental campaigns conducted are summarized in Table 4 (Pontoni et al. 2015, 2016). It is clear that all tested sludge samples have a quite high BMP potential, generally being higher in CAS sludge, but not negligible in the MBR case. Hence, MBR sludge cannot be considered as stabilized; consequently, if not properly disposed, it might cause direct emissions of methane (up to $277 \mathrm{mLCH}_{4} / \mathrm{gVS}$ ) and $\mathrm{CO}_{2}$ (around $40 \%-60 \%$ of the SMP). Concerning the sludge filtration, a wide variance is found among the studied samples, suggesting that the dewatering
Table 4. Specific methane production (SMP) of the tested sludge

\begin{tabular}{lc}
\hline Sludge & SMP $(\mathrm{NmL} / \mathrm{gVS})$ \\
\hline CAS1 & 304 \\
CAS2 & 342 \\
CAS3 & 350 \\
MBR1 & 244 \\
MBR2 & 186 \\
MBR3 & 277 \\
MBR4 & 242 \\
\hline
\end{tabular}

properties mostly depend on the operational parameters and not on the plant configuration (CAS or MBR). Fig. 8 confirms this result; the figure shows a linear correlation between SRF and EPS in the sludge (Pontoni et al. 2016, 2018).

A good fit, according to a linear correlation, has been found for EPS concentrations and SRF values. This result corroborates the prevailing effect of the EPS on the rheological characteristics of the sludge. It is important to point out that the tested sludge comes from different WWTPs characterized by different technologies and operational conditions. If this tendency will be confirmed by other tests carried out on different sludges, the total EPS concentration could be considered a good parameter to predict the sludge dewatering behavior, or, reciprocally, the SRF could provide information concerning the total EPS concentration.

\section{Main Results of RU4}

\section{Monitoring Aerators Fouling and Aging, Optimizing the Schedule of Diffusers Cleaning/Substitution}

For evaluating OTE, a 30,000-PE WWTP was applied using CAS with pre-denitrification and treating on average $12,000 \mathrm{~m}^{3}$ /day of urban wastewater. The WWTP has four treatment lines equipped with extra fine ELASTOX-T bubble disc diffusers (nominal air flow rate $6-8 \mathrm{Nm}^{3} / \mathrm{h} ; 12$ pores $/ \mathrm{cm}^{2}$; disc density $4.3 \%-7.1 \%$ ). A measurement campaign carried out in two parallel aerobic tanks equipped with membrane fine bubble diffusers (Fig. 9). The results allowed to verify the great potential of the off-gas measurements for optimizing aeration devices and potentially reducing energy requirements in WWTPs. Fig. 10 shows the results from the two parallel aerobic tanks, one equipped with new diffusers and the other with aged diffusers. Measurements were carried out along the length of each aerobic tank (plug-flow design) in 12 locations as indicated in Fig. 9 (Gori et al. 2016). A consistent difference in terms of $\alpha S O T E$ between new and aged diffusers was observed. Interestingly, it was possible to conclude that, only due to the fouling of the diffusers, more than double $(117 \%)$ the energy, and 


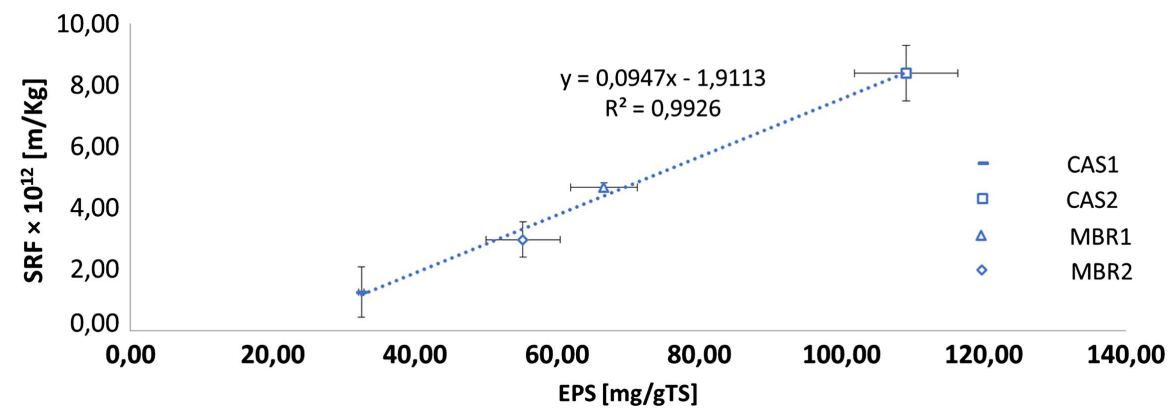

Fig. 8. Linear correlation between the EPS concentration and SRF in the sludge.

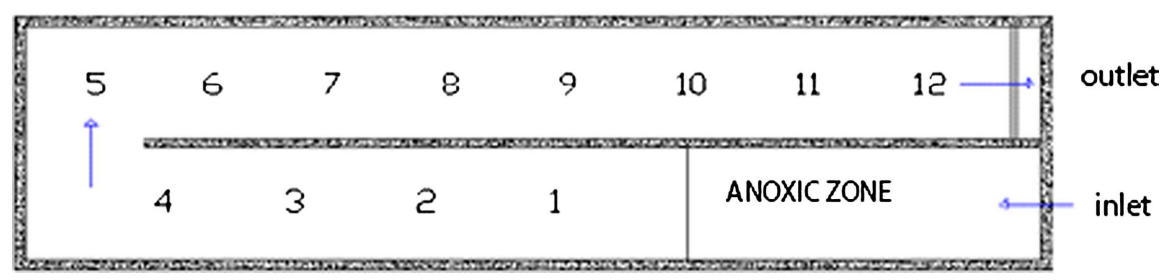

Fig. 9. Top view of the aeration tank with location of measurement points.

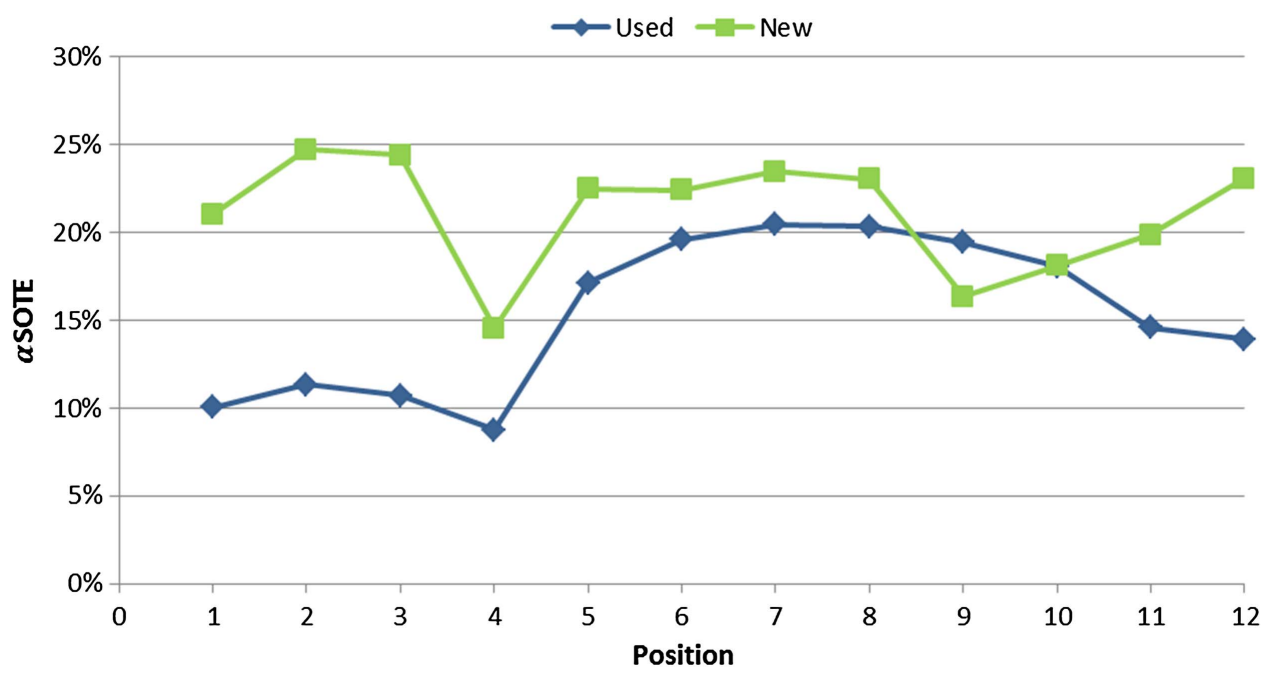

Fig. 10. Effect of diffuser aging on aeration efficiency performances: comparison of OTE results along the length of a plug-flow reactor equipped with used (dots) and new (squares) membrane disc air diffusers.

therefore of operational costs, was needed to provide similar conditions in the tank equipped with aged diffusers as compared to the tank using new diffusers.

In order to estimate the energy and cost savings achievable with the substitution of aged diffusers with new ones, the air-flow rate required for oxidation tank aeration was calculated using the following equation:

$$
\begin{gathered}
Q_{\text {air }}=\frac{O T R}{O T E \cdot \rho_{\mathrm{O}_{2}}} \\
Q=\frac{R_{\mathrm{O} 2}}{O T E \cdot \rho_{\mathrm{O}_{2}}}
\end{gathered}
$$

$O T E$ was calculated considering the average $\alpha S O T E$ of new and aged diffusers, $2 \mathrm{mg} \mathrm{DO} / \mathrm{L}$, and yearly average water temperature. The results are summarized in Table 5 .
In terms of environmental effects, considering $0.406 \mathrm{~kg} \mathrm{CO}_{2} /$ $\mathrm{kWh}$ as the specific emission value (IEA 2012), the energy savings obtained by the replacemente of aged diffusers corresponds to $35.8 \mathrm{tCO}_{2} /$ year (for each treatment line) and $4.8 \mathrm{~kg} \mathrm{CO}_{2} /$ year/ inhabitants.

\section{Effects of Influent Composition and Dynamics on Direct Emissions}

The off-gases exiting the aerobic tanks of two WWTPs (one located in Italy and one in The Netherlands) were monitored for a number of days, in order to understand the origin and the extent of $\mathrm{N}_{2} \mathrm{O}$ emissions. The Italian plant is a CAS system characterized by 12 parallel plug flow bioreactors $(90 \times 6 \times 15 \mathrm{~m})$ with predenitrification and aerated in the second half of their length. The wastewater is usually of very low strength as it is heavily diluted due to surface water infiltration. The Dutch WWTP, on the other hand, is a modified-UCT layout for nitrogen and phosphorous 
Table 5. Estimation of energy and economic savings achievable with the substitution of aged diffusers

\begin{tabular}{lcc}
\hline Energy and economic parameters & Aged diffusers & New diffusers \\
\hline $\begin{array}{l}\text { Average air-flow rate (one } \\
\text { treatment line) }\left(\mathrm{Nm}^{3} / \mathrm{h}\right)\end{array}$ & 900 & 370 \\
$\begin{array}{l}\text { Energy consumption for blower } \\
\text { (one treatment line (MWh/year) }\end{array}$ & 163.4 & 75.3 \\
$\begin{array}{l}\text { Expenditure for energy (one } \\
\text { treatment line) }(€ / \text { year) }\end{array}$ & $\sim 19,600$ & $\sim 9,000$ \\
\hline
\end{tabular}

Note: The energy cost was set at $0.12 € / \mathrm{kWh}$.

removal, employing a carrousel type bioreactor with concentric rings for alternating anaerobic, anoxic, and aerobic conditions.

Large differences in $\mathrm{N}_{2} \mathrm{O}$ emissions (Figs. 11 and 12) were observed between the two WWTPs, but also within the same plant with the fluctuation of the incoming load. These results are in accordance with the literature, confirming the inadequacy of the use of emission factors and the need of a suitable tool for direct and indirect emission assessment (Daelman et al. 2013; Gori et al. 2016, 2017).

The two plants differ mostly for influent composition, and this seems to be the major factor responsible causing the one-fold difference in emission factor. The aeration tank of the Italian WWTP emits $0.027 \mathrm{~g} \mathrm{~N}_{2} \mathrm{O}-\mathrm{N}$ for each gram of $\mathrm{N}$ entering the plant, while the Dutch WWTP emission factor is $0.25 \mathrm{~g} \mathrm{~N}-\mathrm{N}_{2} \mathrm{O} / \mathrm{N}$. Both plants treat municipal wastewater, but the Italian plant suffers from dilution due to infiltration in the sewer (Gori et al. 2016).

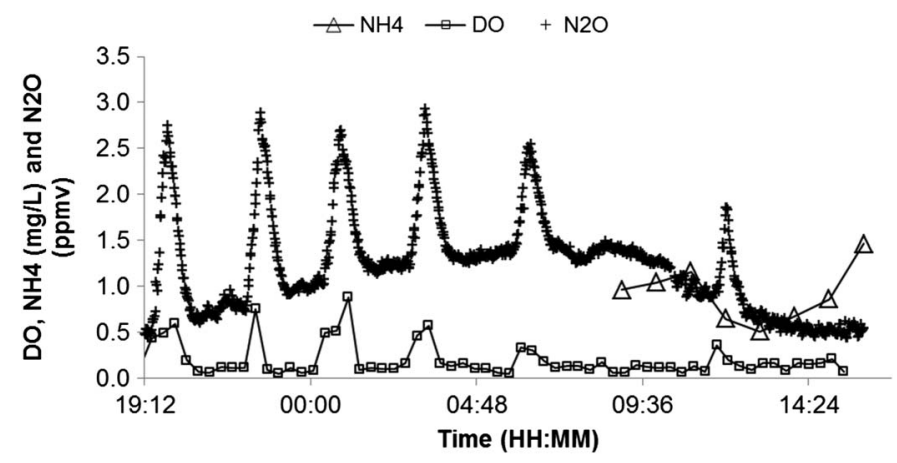

Fig. 11. $\mathrm{N}_{2} \mathrm{O}$ concentrations in the off-gas of a WWTP in Italy.

\section{Conclusion}

WWTPs operate to guarantee high water quality levels at sustainable management costs, as dictated by effluent standards for the safety of receiving water bodies. However, the increasing concerns regarding climate change and environmental protection lead to spend greater efforts in minimizing GHG emissions.

Presently, however, the available scientific literature about the mechanisms occurring in GHG production as well as the amount of emissions is still ongoing and more investigations are needed (Caniani et al. 2015). Therefore, the development of innovative approaches for an integrated WWTP management system is necessary. The most important aim of this project is to carry out experimental activities on full-scale and pilot plants to minimize both direct emissions from biochemical processes and indirect emission from energy consumption, without compromising the effluent quality (Caniani et al. 2015). The authors were able to develop and apply simple and detailed mathematical models thanks to the large database of measurements obtained from the pilot and full-scale experiments.

The main findings are synthesized as follows:

- During MBR treatment, low $\mathrm{C} / \mathrm{N}$ values promote an increase in the $\mathrm{N}_{2} \mathrm{O}-\mathrm{N}$ concentration. Indeed, the average value of $\mathrm{N}_{2} \mathrm{O}-\mathrm{N}$ concentration at $\mathrm{C} / \mathrm{N}=5$ is one order of magnitude greater than that of $\mathrm{C} / \mathrm{N}=10$. This result is likely due to the limited heterotrophic activity at low carbon values. Moreover, the average value of $\mathrm{N}_{2} \mathrm{O}-\mathrm{N}$ concentration increases with the decrease of SRT. This is likely due to the decrease of the autotrophic biomass, which leads to the increase of $\mathrm{N}_{2} \mathrm{O}$ during the nitrification process.

- Regarding the modeling of MBR treatment, by analyzing the obtained results, one concludes that a more thorough model forecast can be acquired with a larger number of measured data $\left(\mathrm{S}_{\mathrm{GHG}, \mathrm{N} 2 \mathrm{O}, 1}\right.$ and $\left.\mathrm{S}_{\mathrm{GHG}, \mathrm{N} 2 \mathrm{O}, 2}\right)$. Thus, a more accurate model prediction can be obtained. This finding is of paramount interest and indicates that large databases are needed to develop accurate models and to decrease the model uncertainty associated with the model predictions. Indeed, $60 \%$ and $46 \%$ of the measured data fall outside the band for $\mathrm{S}_{\mathrm{N} 2 \mathrm{O}, 1}$ and $\mathrm{S}_{\mathrm{N} 2 \mathrm{O}, 2}$, respectively.

- During the first three testing days, $\mathrm{N}_{2} \mathrm{O}$ concentration in the exhausted gas from the pilot-scale aerobic digester had values in the range $0.136-0.344 \mathrm{ppm}$, closed to those obtained in literature from activated sludge units (Butler et al. 2009). Moreover, an increase of $\mathrm{N}_{2} \mathrm{O}$ concentration in the off-gas flow with SRT can be observed. Therefore, as is the case for MBR treatment,

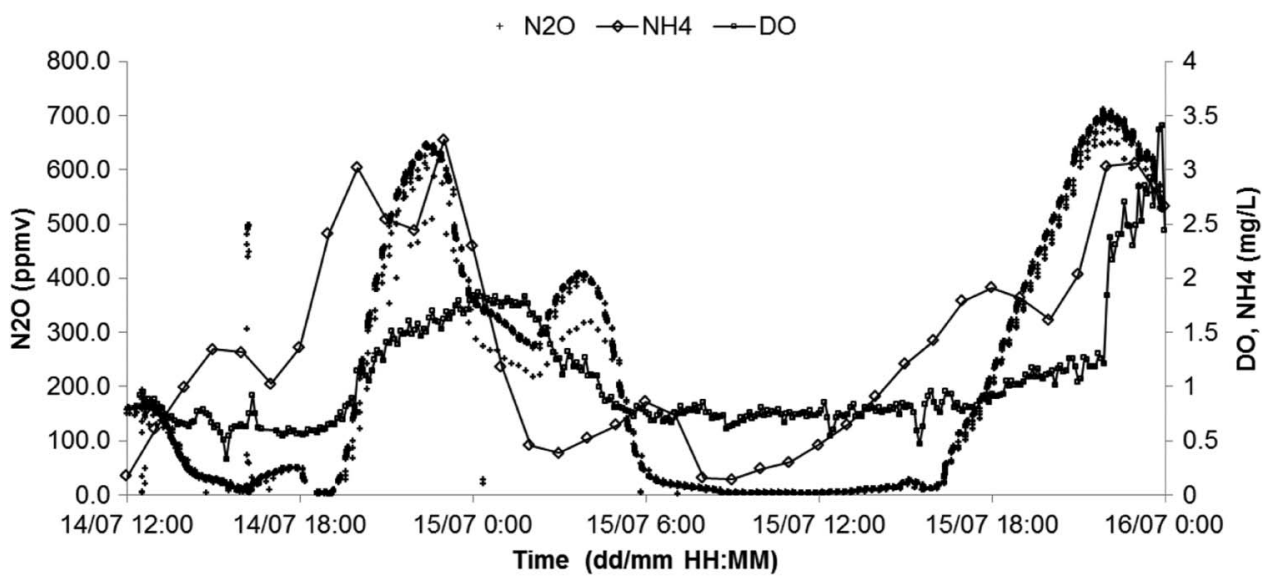

Fig. 12. $\mathrm{N}_{2} \mathrm{O}$ concentrations in the off-gas of a WWTP in The Netherlands. 
it can be concluded that nitrification processes play an important role in $\mathrm{N}_{2} \mathrm{O}$ production during aerobic digestion: a low COD/N ratio leads to an increase of $\mathrm{N}_{2} \mathrm{O}$ production (Desloover et al. 2012).

- The results obtained by BMP tests on both MBR and traditional CAS system sludge show that all tested sludge have a considerable BMP, generally higher in CAS sludge but not negligible in the MBR case. Therefore, since MBR sludge cannot be considered as stabilized, if it is not properly disposed it might cause direct emissions of methane. Concerning the sludge filtration, it is clear that the dewatering properties mostly depend on the operational parameters and not on the plant configuration (CAS or MBR).

- Preliminary results concerning EPS concentrations and SRF values show that the total EPS concentration could bea good parameter to predict dewatering behavior; reciprocally, the SRF could provide information concerning the total EPS concentration.

- All the pilot-scale and full-scale measurements of direct and indirect emissions have been executed by following the protocol proposed by RU4 as a result of this project. This protocol is presented as a standard to measure $\mathrm{CO}_{2}$ and $\mathrm{N}_{2} \mathrm{O}$ emissions along the water and sludge treatment units in both conventional and nonconventional treatment systems.

- A measurement campaign carried out in two parallel aerobic tanks makes it possible to conclude that, only due to the fouling of the diffusers, more than double $(117 \%)$ the energy, and therefore of operational costs, was needed to provide similar conditions in the tank equipped with aged diffusers as compared to the tank using new diffusers. In terms of environmental effects, the energy savings obtained by replacing aged diffusers corresponds to $4.8 \mathrm{~kg} \mathrm{CO}_{2} /$ year/inhabitants.

- Different monitoring campaigns on CAS and UCT WWTPs show large differences in $\mathrm{N}_{2} \mathrm{O}$ emissions among different plants, but also within the same plant with the fluctuation of the incoming loads. These results are in accordance with the literature and confirm the inadequacy of the use of emission factors and the need of a suitable tool for direct and indirect emission assessment. Finally, the influent composition seems to be the major factor responsible for the large fluctuations of $\mathrm{N}_{2} \mathrm{O}$ emissions.

\section{Acknowledgments}

This research was funded by the Italian Ministry of Education, University and Research (MIUR) through the Research project of national interest PRIN2012 (D.M. 28 dicembre 2012 n. 957/Ric-Prot. 2012PTZAMC) entitled "Energy consumption and GreenHouse Gas (GHG) emissions in the wastewater treatment plants: a decision support system for planning and management" in which Giorgio Mannina is the Principal Investigator and Donatella Caniani, Giovanni Esposito and Riccardo Gori are the coordinators of the research units.

\section{Notation}

The following symbols are used in this paper:

$a^{*}=$ mass-specific disintegration surface area $\left(\mathrm{L}^{2}\right)$;

$C_{i}=$ time-dependent dissolved oxygen, $\mathrm{DO}$, in the tank $(\mathrm{mg} / \mathrm{L})$;

$C_{S_{20}}^{*}=\mathrm{DO}$ at saturation at $20^{\circ} \mathrm{C}(\mathrm{mg} / \mathrm{L})$;

$C_{S_{T}}^{*}=\mathrm{DO}$ at saturation at the operating conditions $(\mathrm{mg} / \mathrm{L})$;

$F=$ fouling factor of used diffusers;

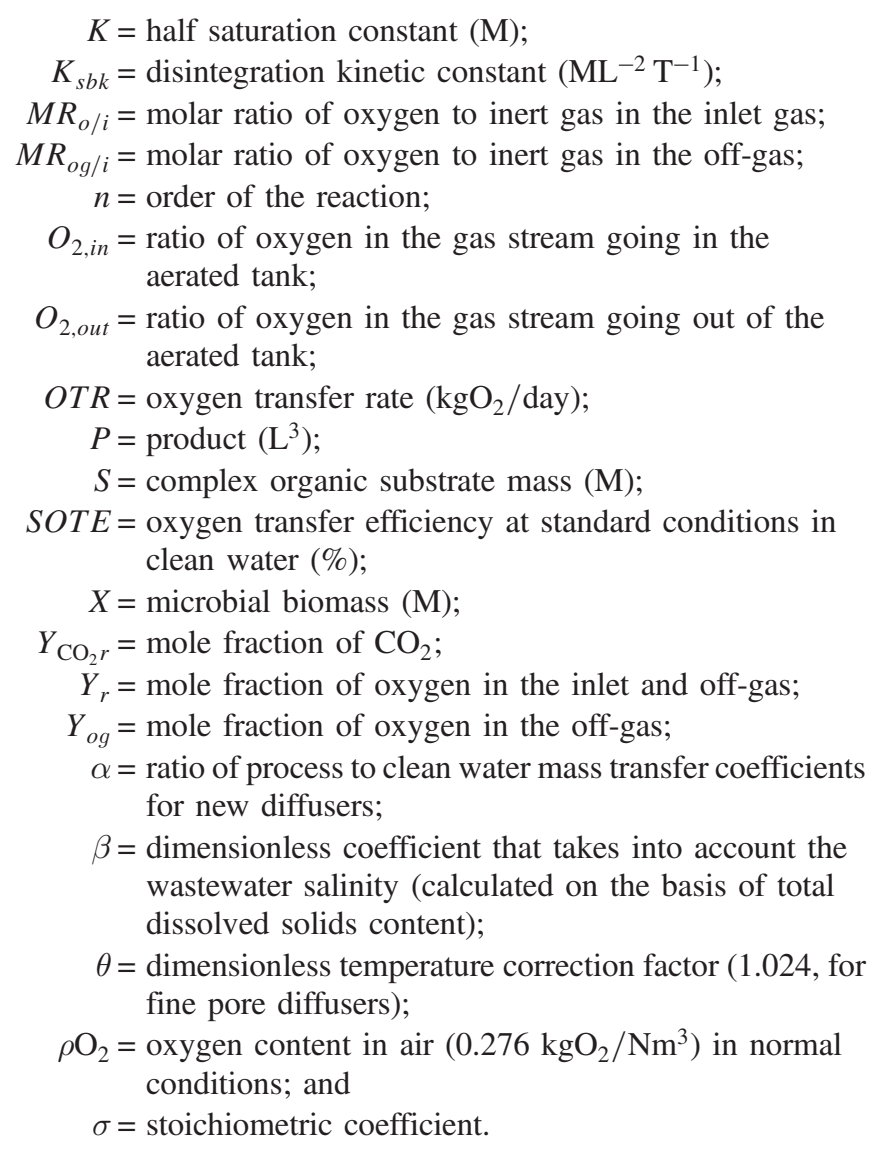

\section{References}

Ahn, J. H., S. Kim, H. Park, B. Rahm, K. Pagilla, and K. Chandran. 2010. " $\mathrm{N}_{2} \mathrm{O}$ emissions from activated sludge processes, 2008-2009: Results of a national monitoring survey in the United States." Environ. Sci. Technol. 44 (12): 4505-4511. https://doi.org/10.1021/es903845y.

APHA, AWWA, and WEF (American Public Health Association, American Water Works Association, and Water Environment Federation). 1998. Standard methods for the examination of water and wastewater. 20th ed. Baltimore: United Book Press.

Bani Shahabadi, M., L. Yerushalmi, and F. Haghighat. 2009. "Impact of process design on greenhouse gas (GHG) generation by wastewater treatment plants." Water Res. 43 (10): 2679-2687. https://doi.org/10 $.1016 /$ j.watres.2009.02.040.

Blumenkrantz, N., and G. Asboe-Hansen. 1973. "New method for quantitative determination of uronic acids." Anal. Biochem. 54 (2): 484-489. https://doi.org/10.1016/0003-2697(73)90377-1.

Butler, M. D., Y. Y. Wang, E. Cartmell, and T. Stephenson. 2009. "Nitrous oxide emissions for early warning of biological nitrification failure in activated sludge." Water Res. 43 (5): 1265-1272. https://doi.org/10 .1016/j.watres.2008.12.027.

Caivano, M., G. Bellandi, I. M. Mancini, S. Masi, R. Brienza, S. Panariello, R. Gori, and D. Caniani. 2017a. "Monitoring the aeration efficiency and carbon footprint of a medium-sized WWTP: Experimental results on oxidation tank and aerobic digester." Environ. Technol. 38 (5): 629-638. https://doi.org/10.1080/09593330.2016.1205150.

Caivano, M., R. Pascale, G. Mazzone, A. Buchicchio, S. Masi, G. Bianco, and D. Caniani. 2017b. " $\mathrm{N}_{2} \mathrm{O}$ and $\mathrm{CO}_{2}$ emissions from secondary settlers in WWTPs: Experimental results on full-and pilot scale plants." In Vol. 4 of Frontiers in wastewater treatment and modelling: Lecture notes in civil engineering, edited by G. Mannina, 412-418. Cham: Springer.

Caivano, M., F. Saluzzi, D. Caniani, S. Masi, and G. Mannina. 2015. "Development of an aerobic digestion model for the assessment of greenhouse gases production (AeDMG1): Calibration and validation." 
In Proc., EuroMed 2015. Rome: European Desalination Society, Univ. Campus Bio-Medico of Rome.

Caniani, D., M. Caivano, R. Pascale, G. Bianco, I. M. Mancini, S. Masi, G. Mazzone, M. Firouzian, and D. Rosso. 2019. " $\mathrm{CO}_{2}$ and $\mathrm{N}_{2} \mathrm{O}$ from water resource recovery facilities: Evaluation of emissions from biological treatment, settling, disinfection, and receiving water body." Sci. Total Environ. 648: 1130-1140. https://doi.org/10.1016/j.scitotenv .2018.08.150.

Caniani, D., A. Cosenza, G. Esposito, L. Frunzo, R. Gori, G. Bellandi, M. Caivano, and G. Mannina. 2017. "A new plant wide modelling approach for the reduction of greenhouse gas emission from wastewater treatment plants." In Vol. 4 of Frontiers in wastewater treatment and modeling: Lecture notes in civil engineering, edited by G. Mannina, 489-496. Cham: Springer.

Caniani, D., G. Esposito, R. Gori, and G. Mannina. 2015. "Towards a new decision support system for design, management and operation of wastewater treatment plants for the reduction of greenhouse gases emission.” Water 7 (10): 5599-5616. https://doi.org/10.3390/w7105599.

Chandran, K. 2011. "Protocol for the measurement of nitrous oxide fluxes from biological wastewater treatment plants." Methods Enzymol. 486: 360-385. https://doi.org/10.1016/S0076-6879(11)86016-7.

Chen, Z., W. Zhang, D. Wang, T. Ma, and R. Bai. 2015. "Enhancement of activated sludge dewatering performance by combined composite enzymatic lysis and chemical re-flocculation with inorganic coagulants: Kinetics of enzymatic reaction and re-flocculation morphology." Water Res. 83 (Oct): 367-376. https://doi.org/10.1016/j.watres.2015.06.026.

Daelman, M. R. J., E. M. van Voorthuizen, L. G. J. M. van Dongen, E. I. P. Volcke, and M. C. M. van Loosdrecht. 2013. "Methane and nitrous oxide emissions from municipal wastewater treatment-Results from a long-term study." Water Sci. Technol. 67 (10): 2350-2355. https://doi .org/10.2166/wst.2013.109.

Desloover, J., S. E. Vlaeminck, P. Clauwaert, W. Verstraete, and N. Boon. 2012. "Strategies to mitigate $\mathrm{N}_{2} \mathrm{O}$ emissions from biological nitrogen removal systems." Curr. Opin. Biotechnol. 23 (3): 474-482. https://doi .org/10.1016/j.copbio.2011.12.030.

Dubois, M., K. A. Gilles, J. K. Hamilton, P. T. Rebers, and F. Smith. 1956. "Colorimetric method for determination of sugars and related substances." Anal. Chem. 28 (3): 350-356.

Esposito, G., L. Frunzo, A. Giordano, F. Liotta, A. Panico, and F. Pirozzi. 2012. "Anaerobic co-digestion of organic wastes." Rev. Environ. Sci. Bio/Technol. 11 (4): 325-341. https://doi.org/10.1007/s11157-012 -9277-8.

Esposito, G., L. Frunzo, A. Panico, and F. Pirozzi. 2011. "Modelling the effect of the OLR and OFMSW particle size on the performances of an anaerobic co-digestion reactor." Process Biochem. 46 (2): 557-565. https://doi.org/10.1016/j.procbio.2010.10.010.

Flores-Alsina, X., L. Corominas, L. Snip, and P. A. Vanrolleghem. 2011. "Including greenhouse gas emissions during benchmarking of wastewater treatment plant control strategies." Water Res. 45 (16): 4700-4710. https://doi.org/10.1016/j.watres.2011.04.040.

Frølund, B., T. Griebe, and P. H. Nielsen. 1995. "Enzymatic activity in the activated-sludge floc matrix." Appl. Microbiol. Biotechnol. 43 (4): 755-761. https://doi.org/10.1007/BF00164784.

Gori, R., et al. 2017. "A novel comprehensive procedure for estimating greenhouse gas emissions from water resource recovery facilities." In Vol. 4 of Frontiers in wastewater treatment and modeling: Lecture notes in civil engineering, edited by G. Mannina, 482-488. Cham: Springer.

Gori, R., G. Bellandi, and C. Caretti, 2016. "Experience, progresses and perspectives of off-gas testing in wastewater treatment: From aeration efficiency towards CFP assessment." In Proc., SIDISA 2016. Roma: DEI Tipografia del Genio Civile.

Gori, R., F. Giaccherini, L. M. Jiang, R. Sobhani, and D. Rosso. 2013. "Role of primary sedimentation on plant-wide energy recovery and carbon footprint." Water Sci. Technol. 68 (4): 870-878. https://doi.org/10 .2166/wst.2013.270.
Guo, J., X. Fu, G. A. Baquero, R. Sobhani, D. A. Nolasco, and D. Rosso. 2016. "Trade-off between carbon emission and effluent quality of activated sludge processes under seasonal variations of wastewater temperature and mean cell retention time." Sci. Total Environ. 547 (Mar): 331-344. https://doi.org/10.1016/j.scitotenv.2015.12.102.

IEA (International Energy Agency). 2012. $\mathrm{CO}_{2}$ emissions from fuel combustion. Paris: IEA.

Kampschreur, M. J., H. Temmink, R. Kleerebezem, M. S. Jetten, and M. C. van Loosdrecht. 2009. "Nitrous oxide emission during wastewater treatment." Water Res. 43 (17): 4093-4103. https://doi.org/10 .1016/j.watres.2009.03.001.

Kim, S. W., M. Miyahara, S. Fushinobu, T. Wakagi, and H. Shoun. 2010. "Nitrous oxide emission from nitrifying activated sludge dependent on denitrification by ammonia-oxidizing bacteria." Bioresour. Technol. 101 (11): 3958-3963. https://doi.org/10.1016/j.biortech.2010.01.030.

Kintner, P. K., III, and J. P. Van Buren. 1982. "Carbohydrate interference and its correction in pectin analysis using the m-hydroxydiphenyl method." J. Food Sci. 47 (3): 756-759. https://doi.org/10.1111/j.1365 -2621.1982.tb12708.x.

Lowry, O. H., N. J. Rosenbrough, A. Farr, and R. J. Randall. 1951. "Protein measurement with the Folin phenol reagent." J. Biol. Chem. 193 (1): $265-275$.

Mannina, G., M. Capodici, A. Cosenza, and D. Di Trapani. 2016a. "Carbon and nutrient biological removal in a University of Cape Town membrane bioreactor: Analysis of a pilot plant operated under two different C/N ratios." Chem. Eng. J. 296 (Jul): 289-299. https://doi.org/10.1016/j .cej.2016.03.114.

Mannina, G., G. Ekama, D. Caniani, A. Cosenza, G. Esposito, R. Gori, M. Garrido-Baserba, D. Rosso, and G. Olsson. 2016b. "Greenhouse gases from wastewater treatment: A review of modelling tools." Sci. Total Environ. 551-552 (May): 254-270. https://doi.org/10.1016/j .scitotenv.2016.01.163.

Mannina, G., C. Morici, A. Cosenza, D. Di Trapani, and H. Odegaard. 2016c. "Greenhouse gases from sequential batch membrane bioreactors: A pilot plant case study." Biochem. Eng. J. 112 (Aug): 114-122. https://doi.org/10.1016/j.bej.2016.04.010.

Metcalf \& Eddy. 2003. Wastewater engineering: Treatment and reuse. 4th ed. New York: McGraw-Hill.

Pontoni, L., et al. 2018. "Dewaterability of CAS and MBR sludge: Effect of biological stability and EPS composition." J. Environ. Eng. 144 (1): 04017088. https://doi.org/10.1061/(ASCE)EE.1943-7870 .0001299 .

Pontoni, L., G. D'Alessandro, G. D'Antonio, G. Esposito, M. Fabbricino, L. Frunzo, and F. Pirozzi, 2015. "Effect of anaerobic digestion on rheological parameters and dewaterability of aerobic sludges from MBR and conventional activated sludge plants." Chem. Eng. Trans. 43: 2311-2316. https://doi.org/10.3303/CET1543386.

Pontoni, L., M. Fabbricino, L. Frunzo, F. Pirozzi, and G. Esposito. 2016. "Biological stability and dewaterability of CAS and MBR sludge." Desalin. Water Treat. 57 (48-49): 22926-22933. https://doi.org/10 .1080/19443994.2016.1153904.

Stenström, F., K. Tjus, and J. la Cour Jansen. 2014. "Oxygen-induced dynamics of nitrous oxide in water and off-gas during the treatment of digester supernatant." Water Sci. Technol. 69 (1): 84-91. https://doi .org/10.2166/wst.2013.558.

USEPA Office of Water. 2001. METHOD 1684-Total, fixed, and volatile solids in water, solids, and biosolids. EPA-821-R-01-015. Washington, DC: Office of Science and Technology Engineering and Analysis Division.

Wu, G., D. Zheng, and L. Xing. 2014. "Nitritation and $\mathrm{N}_{2} \mathrm{O}$ emission in a denitrification and nitrification two-sludge system treating high ammonium containing wastewater." Water 6 (10): 2978-2992. https://doi.org /10.3390/w6102978.

Yu, R., M. J. Kampschreur, M. C. M. Loosdrecht, and K. Chandran. 2010. "Mechanisms and specific directionality of autotrophic nitrous oxide and nitric oxide generation during transient anoxia." Environ. Sci. Technol. 44 (4): 1313-1319. https://doi.org/10.1021/es902794a. 